\title{
Furaldehyde substrate specificity and kinetics of Saccharomyces cerevisiae alcohol dehydrogenase 1 variants
}

\author{
Boaz Laadan', Valeria Wallace-Salinas', Åsa Janfalk Carlsson², João RM Almeida ${ }^{3}$, Peter Rådström \\ and Marie F Gorwa-Grauslund ${ }^{1 *}$
}

\begin{abstract}
Background: A previously discovered mutant of Saccharomyces cerevisiae alcohol dehydrogenase 1 (Adh1p) was shown to enable a unique NADH-dependent reduction of 5-hydroxymethylfurfural (HMF), a well-known inhibitor of yeast fermentation. In the present study, site-directed mutagenesis of both native and mutated ADH1 genes was performed in order to identify the key amino acids involved in this substrate shift, resulting in Adh1p-variants with different substrate specificities.

Results: In vitro activities of the Adh1p-variants using two furaldehydes, HMF and furfural, revealed that HMF reduction ability could be acquired after a single amino acid substitution (Y295C). The highest activity, however, was reached with the double mutation S110P Y295C. Kinetic characterization with both aldehydes and the in vivo primary substrate acetaldehyde also enabled to correlate the alterations in substrate affinity with the different amino acid substitutions.

Conclusions: We demonstrated the key role of Y295C mutation in HMF reduction by Adh1p. We generated and kinetically characterized a group of protein variants using two furaldehyde compounds of industrial relevance. Also, we showed that there is a threshold after which higher in vitro HMF reduction activities do not correlate any more with faster in vivo rates of HMF conversion, indicating other cell limitations in the conversion of HMF.
\end{abstract}

Keywords: Alcohol dehydrogenase, NADH, Site-directed mutagenesis, Furfural, HMF

\section{Background}

Cost-efficient bioethanol production from lignocellulosic hydrolysates is in demand nowadays as a renewable liquid fuel $[1,2]$. However, the efficient fermentation of the complex raw material confronts several challenges, one of which being growth-inhibiting substances released during pretreatment and hydrolysis of lignocellulose [3]. During pretreatment of the biomass, two furaldehydes, HMF (5-hydroxymethylfurfural) and 2-furfural, are produced as the result of dehydration of hexose and pentose sugars, respectively $[4,5]$. Both HMF and furfural inhibit growth of S. cerevisiae and show synergistic effects [6]. Other reported effects include the decrease in ethanol

\footnotetext{
* Correspondence: Marie-Francoise.Gorwa@tmb.Ith.se

'Applied Microbiology, Department of Chemistry, Lund University, P.O. Box 124, SE-22100 Lund, Sweden

Full list of author information is available at the end of the article
}

yield and productivity [7] and the inhibition of several key enzymes by furfural [8], among which is alcohol dehydrogenase (EC 1.1.1.1). Native S. cerevisiae cells are able to reduce HMF and furfural in vivo to the less inhibitory alcohols $[6,9]$, however at a low and straindependent rate.

We previously isolated and characterized a mutated gene variant of S. cerevisiae ADH1 [10] from strain TMB3000, found at a spent sulfite liquor fermentation plant [11]. Whereas native Adh1p (natAdh1p) primarily catalyzes the reduction of acetaldehyde to ethanol using $\mathrm{NADH}$ as a co-factor [12], and was shown to reduce the smaller molecule formaldehyde [13], the mutated variant (mutAdh1p) also reduced the larger compound HMF using NADH as a co-factor [10]. All other known S. cerevisiae HMF reductases, including Adh6p, had been described as being NADPH dependent [14]. The nucleotide sequence of 
mutAdh1p revealed six amino acid substitutions [10]. While three of the reported mutations were present in previously published sequences [15] the other three mutations were novel and shown to reside in the vicinity of the substrate-binding pocket [10].

In the present study, the effect of individual mutations was evaluated through site-directed mutagenesis of both natAdh1p (Figure 1) and mutAdh1p. The different variants displayed a wide range of reduction rates with several substrates and the comparison revealed the effects of both novel and previously reported mutations. Five variants were kinetically characterized, revealing distinct differences between affinity constants and maximal velocity values for both furaldehyde and acetaldehyde substrates. The variant displaying the highest in vitro activity with HMF was evaluated for in vivo HMF reduction.

\section{Results}

Generation and in vitro activity of Adh1p-variants

In the present study we generated a group of Adh1pvariants based on six mutations previously identified in the industrial S. cerevisiae strain TMB3000. Through enzymatic assays using the furaldehyde compounds HMF and furfural, alterations in the reduction capacity of the variants were analyzed in relation to the amino acid changes.

The first three variants were created by mutagenesis of the originally isolated mutated $A D H 1$ gene from TMB3000

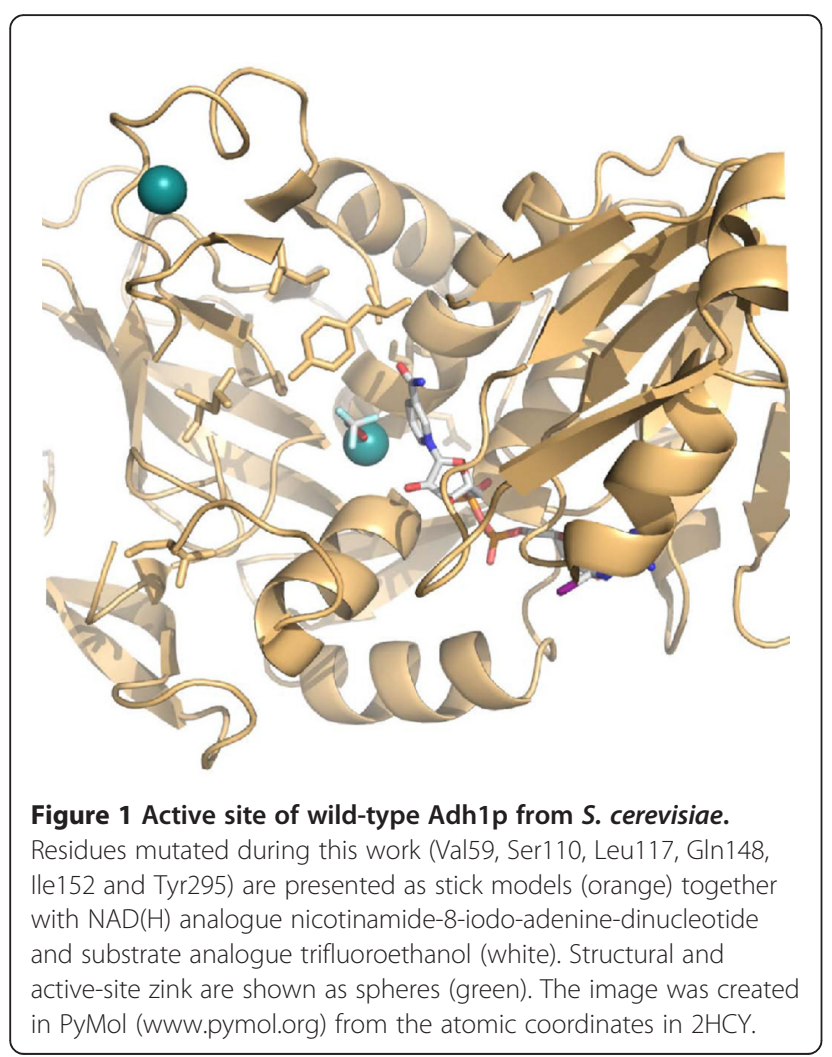

[10] encoding a protein designated here as mutAdh1p (Table 1). The three novel mutations found within the protein (S110P, L117S, Y295C) were changed individually back to their native state. The resulting protein variants were designated, respectively, mutAdh1p-rev110, mutAdh1p-rev117 and mutAdh1p-rev295 (Table 1).

$\mathrm{NADH}$-dependent reduction of HMF and furfural were compared using the lysate of the strains carrying the three new Adh1p-variants, the strain carrying mutAdh1p and a control strain (reference plasmid) (Figure 2). mutAdh1p exhibited an HMF activity of $0.80 \mathrm{U} / \mathrm{mg}$ total protein, while cell extract of the reference strain showed no activity with HMF. The three mutants, however, showed a significant change of activity with altering a single amino acid. Reversion at position 110 (mutAdh1p-rev110) led to over $80 \%$ reduction in HMF activity $(0.13 \mathrm{U} / \mathrm{mg}$ total protein), while reversion at position 295 (mutAdh1p-rev295) abolished HMF activity, indicating a potential role in the acquired HMF reduction ability. In contrast, reversion at position 117 (mutAdh1p-rev117) led to a 3-fold increase $(2.39 \mathrm{U} / \mathrm{mg}$ total protein) in specific activity against HMF (Figure 2).

With furfural, mutAdh1p showed an activity of 0.78 $\mathrm{U} / \mathrm{mg}$ total protein while the control strain showed a decrease of over $40 \%$ to $0.42 \mathrm{U} / \mathrm{mg}$ total protein (Figure 2). Each reversion led to an increase in furfural reduction: more than 20\% (0.99 U/mg total protein and $0.98 \mathrm{U} / \mathrm{mg}$ total protein) for mutAdh1p-rev110 and mutAdh1rev295, respectively and almost a 3 -fold increase in activity for mutAdh1p-rev117 (2.20 U/mg total protein).

In view of these results, natAdh1p was mutated at positions 110 and 295. Native $A D H 1$ gene was amplified from genomic DNA of CEN.PK 113-5D and overexpressed in the same strain (designated CEN.PK 113-5D [natAdh1p]). Site-directed mutagenesis of native $A D H 1$ resulted in two more protein variants designated natAdh1p-m110 (S110P) and natAdh1p-m295 (Y295C) (Table 1). NADH-dependent HMF and furfural activities

Table 1 Amino acid changes among the different Adh1p-variants

\begin{tabular}{lllllll}
\hline Variant & \multicolumn{2}{l}{ Position } & & & \\
\cline { 2 - 6 } & $\mathbf{5 9}$ & $\mathbf{1 1 0}$ & $\mathbf{1 1 7}$ & $\mathbf{1 4 8}$ & $\mathbf{1 5 2}$ & $\mathbf{2 9 5}$ \\
\hline natAdh1p & V & S & L & Q & I & Y \\
mutAdh1p & T & P & S & E & V & C \\
mutAdh1p-rev110 & T & S & S & E & V & C \\
mutAdh1p-rev117 & T & P & L & E & V & C \\
mutAdh1p-rev295 & T & P & S & E & V & Y \\
natAdh1p-m110 & V & P & L & Q & I & Y \\
natAdh1p-m295 & V & S & L & Q & I & C \\
natAdh1p-m110, 295 & V & P & L & Q & I & C \\
mutAdh1p-rev110,117 & T & S & L & E & V & C \\
\hline
\end{tabular}




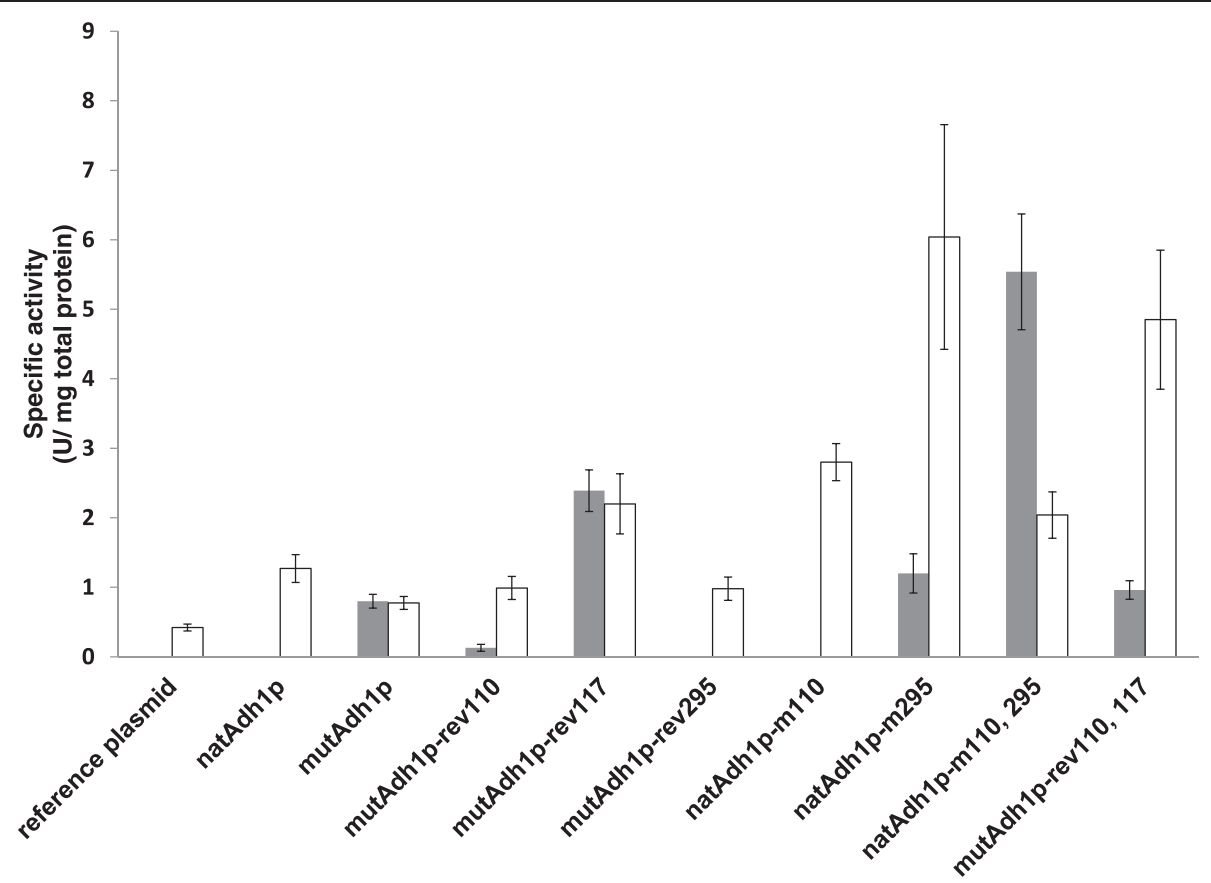

Figure 2 Specific activity against HMF (filled bars) and furfural (empty bars) of strains carrying different variants of Adh1p (see Table 1 for description). Absence of bar means not activity could be detected. One unit (U) corresponds to $1 \mu$ mol of NADH oxidized per min, at $30^{\circ} \mathrm{C}$ and pH 6.7 .

were determined for the newly constructed strains (Figure 2). As expected from previous results, natAdh1p showed no activity against HMF. natAdh1p-m110 did not show activity with HMF either. natAdh1p-m295, on the contrary, showed an activity of $1.20 \mathrm{U} / \mathrm{mg}$ total protein, which represents a 50\% increase compared with mutAdh1p. With furfural, all variants displayed a considerable increase in activity as compared with mutAdh1p: over $60 \%$ for natAdh1p (1.27 U/mg total protein) as well as 3.6 -fold ( $2.80 \mathrm{U} / \mathrm{mg}$ total protein) and 7.7 -fold (6.04 U/mg total protein) increase for natAdh1p-m110 and natAdh $1 \mathrm{p}-\mathrm{m} 295$, respectively (Figure 2 ).

In order to further understand how different amino acids influenced the substrate specificity of Adh1p, two more mutants were created. NatAdh1p was mutated at positions S110P and Y295C, and named natAdh1-m110, 295 (Table 1). In mutAdh1p two changes, P110S and S117L were performed, resulting in variant mutAdh1prev110, 117. Reversion at positions 110 and 117 gave slightly higher HMF activity $(0.96 \mathrm{U} / \mathrm{mg}$ total protein) than mutAdh1p but the highest HMF activity of all variants was obtained for natAdh1p-m110, 295 (5.54 U/mg total protein) (Figure 2). Furfural activity was high for both new variants, with $4.85 \mathrm{U} / \mathrm{mg}$ total protein for mutAdh1p-rev110, 117 and $2.04 \mathrm{U} / \mathrm{mg}$ total protein for natAdh1-m110, 295 (Figure 2).

The possible effect of $A D H 1$ gene dosage on Adh1p activities was determined using a relative quantification assessment of plasmid copy number between strains carrying mutAdh1p and natAdh1p-m110, 295. qPCR data showed indistinguishable quantification values between both strains (data not shown). Therefore, since no difference in plasmid copy number was observed between these strains at the moment of harvesting, the differences in activities previously described with both furaldehydes are rather a direct result of the mutations in the $A D H 1$ gene. In addition, and considering that all strains were harvested at comparable physiological state and cell density, it is very likely that the amino acid substitutions, rather that differences in gene dosage, are also responsible for the variations in activities observed between the other strains.

\section{Kinetics of Adh1p-variants}

Variants natAdh1p, mutAdh1p and its derivative that was reverted at position 117 (mutAdh1p-rev117), as well as natAdh1p-m110, 295 and mutAdh1p-rev110, 117 were further kinetically characterized. Kinetic parameters were determined by introducing the corresponding genes in strain BY4741 that lacked $A D H 1$ gene (Table 2) and measuring NADH-dependent HMF, furfural and acetaldehyde reduction in the cell extracts. The parameters Vmax, Km and $\mathrm{Ki}$ were determined from the model described in the section Materials and methods; where the parameter $K_{\mathrm{i}}$ represents the inhibition factor, with higher values implying lower inhibition. $[\mathrm{S}]_{V \max }$ represents the substrate concentration at which the experimental Vmax (observed $\mathrm{V}_{\max }$ ) was measured. The RSQ value stands 
Table 2 Strains used in the study

\begin{tabular}{|c|c|c|}
\hline S. cerevisiae strains & Relevant genotype & Reference \\
\hline CEN.PK 113-5D & Mata ura3 & {$[16]$} \\
\hline Control (reference plasmid) & CEN.PK 113-5D, YEplacHXT & [10] \\
\hline CEN.PK 113-5D [natAdh1p] & CEN.PK 113-5D, YEplacHXT-natADH1 & This study \\
\hline CEN.PK 113-5D [mutAdh1p] & CEN.PK 113-5D, YEplacHXT-mutADH1 & [10] \\
\hline CEN.PK 113-5D [mutAdh1p-rev110] & CEN.PK 113-5D, YEplacHXT-mutADH1-rev110 & This study \\
\hline CEN.PK 113-5D [mutAdh1p-rev117] & CEN.PK 113-5D, YEplacHXT-mutADH1-rev117 & This study \\
\hline CEN.PK 113-5D [mutAdh1p-rev295] & CEN.PK 113-5D, YEplacHXT-mutADH1-rev295 & This study \\
\hline CEN.PK 113-5D [natAdh1p-m110] & CEN.PK 113-5D, YEplacHXT-natADH1-m110 & This study \\
\hline CEN.PK 113-5D [natAdh1 p-m295] & CEN.PK 113-5D, YEplacHXT-natADH1-m295 & This study \\
\hline CEN.PK 113-5D [natAdh1p-m110, 295] & CEN.PK 113-5D, YEplacHXT-natADH1-m110, 295 & This study \\
\hline CEN.PK 113-5D [mutAdh1p-rev110, 117] & CEN.PK 113-5D, YEplacHXT-mutADH1-rev110, 117 & This study \\
\hline BY4741 & $\begin{array}{l}\text { Mat-a his } 3 \Delta 1 \text { leu2 } \Delta 0 \text { met15 } 50 \text { ura3 } \Delta 0 \text {, } \\
\text { deleted ORF YOL086C (adh1) }\end{array}$ & EUROSCARF collection, Heidelberg, Germany \\
\hline BY4741 [natAdh1p] & BY4741, YEplacHXT-natADH1 & This study \\
\hline BY4741 [mutAdh1p] & BY4741, YEplacHXT-mutADH1 & This study \\
\hline BY4741 [mutAdh1p-rev117] & BY4741, YEplacHXT-mutADH1-rev117 & This study \\
\hline BY4741 [natAdh1p-m110,295] & BY4741, YEplacHXT-natADH1-m110, 295 & This study \\
\hline BY4741 [mutAdh1p-rev1 10,117] & BY4741, YEplacHXT-mutADH1-rev110, 117 & This study \\
\hline
\end{tabular}

for coefficient of determination $R^{2}$, describing the variability between the data set and the statistical model, with value 1 specifying a perfect correlation. The background activity in cell extract of the $\Delta$ Adh 1 strain was low for all the substrates $(0.02 \mathrm{U} / \mathrm{mg}$ total protein for acetaldehyde and furfural; $0.01 \mathrm{U} / \mathrm{mg}$ total protein for HMF).

The cell cultures of the different BY4741 strains used for kinetic characterization were harvested at the same physiological state and comparable cell densities, and the analysis focused on the differences in activities (with HMF and furfural) within each variant in relation to the natural substrate acetaldehyde.

The results from the kinetic characterization showed that the various mutations altered the activity of the variants with the substrates to different extent (Table 3). For natAdh1p, HMF activity was not detected, while the activity with furfural was about $14 \%$ of that measured with acetaldehyde. The variant mutAdh1p, on the other hand, showed activity with HMF, corresponding to about $66 \%$ of the activity obtained with acetaldehyde as substrate. For this variant, the activity with furfural was lower than that with HMF, since it was only around 34\% of that obtained with acetaldehyde (Table 3). The other variant studied, mutAdh1p-rev117 showed a different preference in substrate. This variant displayed, with HMF and furfural respectively, around $27 \%$ and $50 \%$ of the activity obtained with acetaldehyde (Table 3 ). The variant natAdh1p-m110, 295 showed similar ratios on activities as the mutAdh1p, that is, its activity with HMF was close to $70 \%$ of the activity measured with acetaldehyde, and with furfural only around $34 \%$ of that obtained with the reference substrate. Finally, mutAdh1prev110, 117 showed a low activity with HMF and furfural (11\% and $24 \%$ of the activity obtained with acetaldehyde respectively) (Table 3 ).

The kinetics also highlighted differences in affinity constant $(\mathrm{Km})$ and substrate inhibition constants (Ki) between the substrates (Table 4). For natAdh1p, the affinity constant $K_{m}$ was much lower for acetaldehyde than for furfural (0.22 mM vs. $18.80 \mathrm{mM})$. However, this variant did not show inhibition by furfural at concentrations up to $30 \mathrm{mM}$, while inhibition by acetaldehyde was observed around $1 \mathrm{mM}$ (Table 4). The $\mathrm{K}_{\mathrm{m}}$ values obtained for mutAdh1p were $1.69 \mathrm{mM}$ (acetaldehyde), $4.30 \mathrm{mM}$ (HMF) and $0.04 \mathrm{mM}$ (furfural) (Table 4).

Table 3 Ratio of activities for the Adh1p-variants with substrates HMF and furfural in relation to the activity obtained with the natural substrate acetaldehyde during the kinetic characterization

\begin{tabular}{|c|c|c|c|c|c|}
\hline Ratio of activities & natAdh1p & mutAdh1p & mutAdh1p-rev117 & natAdh1p-m110, 295 & mutAdh1p-rev110, 117 \\
\hline$\frac{V \text { max HMF }}{V \text { max acetaldehyde }}$ & 0.00 & 0.66 & 0.27 & 0.67 & 0.11 \\
\hline$\frac{V \text { max furfural }}{V \text { max acetaldehyde }}$ & 0.14 & 0.34 & 0.51 & 0.34 & 0.24 \\
\hline
\end{tabular}


Table 4 Kinetic parameters of the Adh1p-variants with acetaldehyde, HMF and furfural as substrates

\begin{tabular}{|c|c|c|c|c|c|c|}
\hline Variant & Substrates & Vmax (mU/mg) & $\mathrm{Km}(\mathrm{mM})$ & $\mathrm{Ki}(\mathrm{mM})$ & {$[S]_{V_{\max }}\left(o b s V_{\max }\right)^{*}$} & RSQ \\
\hline \multirow[t]{3}{*}{ natAdh1p } & Acetaldehyde & 45070 & 0.22 & 12.53 & $1(35300)$ & 0.987 \\
\hline & $H M F$ & Not detected & & & & \\
\hline & Furfural & 6530 & 18.8 & 1363 & $30(4345)$ & 0.970 \\
\hline \multirow[t]{3}{*}{ mutAdh1p } & Acetaldehyde & 4736 & 1.69 & 49 & $10(3700)$ & 0.968 \\
\hline & $H M F$ & 3120 & 4.30 & 9.82 & 5-10 (1320) & 0.984 \\
\hline & Furfural & 1625 & 0.04 & 1.07 & $0.25(1230)$ & 0.974 \\
\hline \multirow[t]{3}{*}{ mutAdh1p-rev117 } & Acetaldehyde & 23060 & 1.74 & 96 & $10-25(17600)$ & 0.979 \\
\hline & $H M F$ & $6320^{* *}$ & 4.28 & n.d & $10(4900)$ & 0.975 \\
\hline & Furfural & 11700 & 0.33 & 4.40 & $1(7600)$ & 0.992 \\
\hline \multirow[t]{3}{*}{ natAdh1p-m110, 295} & Acetaldehyde & 16509 & 0.83 & 46 & $5(14300)$ & 0.970 \\
\hline & $H M F$ & 11090 & 9.45 & 20.80 & $10-20(4560)$ & 0.999 \\
\hline & Furfural & 5657 & 0.13 & 1.32 & $0.25-0.5(3480)$ & 0.984 \\
\hline \multirow[t]{3}{*}{ mutAdh1p-rev110,117 } & Acetaldehyde & 32455 & 3.03 & 56 & $10(22000)$ & 0.974 \\
\hline & HMF & 3640 & 13.10 & 27.30 & $20(1550)$ & 0.980 \\
\hline & Furfural & 7792 & 0.34 & 6.66 & $1(5320)$ & 0.986 \\
\hline
\end{tabular}

* $[S]_{\operatorname{Vmax}}$ - substrate concentration $(\mathrm{mM})$ at observed $\mathrm{V}_{\max }\left(\right.$ obs $\left.\mathrm{V}_{\max }, \mathrm{mU} / \mathrm{mg}\right)$, ${ }^{* *} \mathrm{~V}_{\max }$ and $\mathrm{K}_{\mathrm{m}}$ values derived from a model without substrate inhibition factor, see text for details.

Inhibition with acetaldehyde and HMF was observed around concentration of $10 \mathrm{mM}$ of these substrates, while with furfural inhibition was observed at lower concentrations (around $0.25 \mathrm{mM}$ ). For the variant mutAdh1prev117, the $\mathrm{K}_{\mathrm{m}}$ values obtained were $1.74 \mathrm{mM}, 4.28 \mathrm{mM}$ and $0.33 \mathrm{mM}$ for acetaldehyde, HMF and furfural respectively (Table 4). Inhibition by acetaldehyde was observed above $25 \mathrm{mM}$, for HMF around $10 \mathrm{mM}$ while with furfural above $1 \mathrm{mM}$. For natAdh1p-m110, 295, the $K_{m}$ values were lower than one for acetaldehyde $(0.83 \mathrm{mM})$ and furfural $(0.13 \mathrm{mM})$, and with HMF the $\mathrm{K}_{\mathrm{m}}$ calculated was $9.35 \mathrm{mM}$. This variant was less inhibited by HMF (above $20 \mathrm{mM}$ ) than by acetaldehyde (inhibition observed above $5 \mathrm{mM}$ ). With furfural, however, inhibition was observed at concentrations above $0.50 \mathrm{mM}$. Finally, the $\mathrm{Km}$ values obtained for mutAdh1p-rev110, 117 were $3.03 \mathrm{mM}, 13.10 \mathrm{mM}$ and $0.34 \mathrm{mM}$ for acetaldehyde, HMF and furfural respectively. Inhibition by acetaldehyde was observed at concentrations above $10 \mathrm{mM}$, while inhibition by HMF and furfural were evident above $20 \mathrm{mM}$ and $1 \mathrm{mM}$ respectively (Table 4).

\section{In vivo HMF conversion}

Anaerobic batch fermentations in the presence of $2 \mathrm{~g} / \mathrm{L}$ HMF were carried out to compare the in vivo HMF reduction capacity of strain CEN.PK 113 5D [mutAdh1p] and the strain showing the highest in vitro HMF/acetaldehyde reduction ratio CEN.PK 113 5D [natAdh1p-mut110, 295]. A control strain carrying a reference plasmid was also included. The concentration of HMF was chosen according to levels previously reported in spruce hydrolysate [17].
The in vivo HMF uptake rate of the control strain $(0.14 \mathrm{~g} / \mathrm{g}$ cell. $\mathrm{h})$ was the same as the one previously reported for the S. cerevisiae strain CBS 8066 under similar conditions [6]. For the strains carrying the two mutants, the in vivo values were equivalent, and more than three times higher than for the control strain (Table 5). In agreement with this result, both strains overexpressing the mutated $A D H 1$ genes performed very similarly during the fermentations (Figure 3 , Table 5) and displayed much higher glucose consumption rate than the control strain (Table 5). Strains overexpressing $A D H 1$ also showed slightly lower concentrations of glycerol when compared to the control. But final ethanol yields and product distribution was similar for the rest of metabolites between the three strains (Table 6). When the values of in vitro specific activity were compared with the in vivo rates of HMF uptake, it was found that the capacity for HMF reduction in vitro was around five times and thirty seven times higher (for CEN.PK 113-5D [mutAdh1p] and CEN.PK 113-5D [natAdh1p-m110, 295] respectively) than during the fermentations (Table 5).

\section{Discussion}

The study aimed at unraveling the importance of the different mutations identified in a previously described Adh1p mutant displaying an unusual NADH-dependent HMF reductase activity [10]. Here we demonstrated the key role of Y295C mutation in HMF reduction, but also the overall negative impact of L117S mutation on furaldehyde reduction. We previously hypothesized that the replacement of tyrosine with cysteine at position 295 resulted in the widening of the substrate binding pocket, 
Table 5 In vitro and in vivo conversion rate of HMF and specific growth, glucose consumption and ethanol production rates in anaerobic batch fermentation in defined mineral medium supplemented with 2 g/l HMF

\begin{tabular}{llllll}
\hline Strain & $\begin{array}{l}\text { In vitro HMF reduction } \\
\text { (g/g cells. } \mathbf{~})\end{array}$ & $\begin{array}{l}\text { In vivo conversion rate } \\
\text { (g/g cells.h) }\end{array}$ & $\boldsymbol{\mu}(\mathbf{1 / h})$ & $\begin{array}{l}\mathbf{q}_{\text {glucose }} \\
\text { (g/g cells. } \mathbf{h})\end{array}$ & $\begin{array}{l}\mathbf{q}_{\text {ethanol }} \\
\text { (g/g cells. } \mathbf{h})\end{array}$ \\
\hline Control & nd $^{b}$ & $0.14 \pm 0.00$ & $0.07 \pm 0.00$ & $1.54 \pm 0.09$ & $0.58 \pm 0.06$ \\
CEN.PK 113-5D [mutAdh1 p] & $2.57 \pm 0.32$ & $0.47 \pm 0.03$ & $0.13 \pm 0.01$ & $2.96 \pm 0.63$ & $1.19 \pm 0.09$ \\
CEN.PK 113-5D [natAdh1 p-m110, 295] & $17.81 \pm 2.68$ & $0.48 \pm 0.00$ & $0.13 \pm 0.01$ & $3.08 \pm 0.70$ & $1.17 \pm 0.16$ \\
\hline
\end{tabular}

${ }^{a}$ The in vitro activities for these strains were recalculated as gHMF converted per gram of cells per hour. This allowed the comparison between the conversion rates during the fermentation and the in vitro measurements. ${ }^{b}$ Not detected.

Rates were calculated during exponential growth. Presented values are the mean of two independent biological replicates.

by enabling the accommodation of the bulky HMF molecule [10]. However, natAdh1p can reduce the bulky furfural substrate, as displayed here and elsewhere [18]. We therefore speculate that acquisition of HMF and increase in furfural reduction capability by Y295C mutation relies not only on an enlarged binding pocket, but also in the differences in properties, such as the polarity of the side chain, between tyrosine and cysteine. We also demonstrated that the acquired mutation at position 117, whose neighbor amino acids belong to the substratebinding pocket [19], was disadvantageous for furaldehyde reduction as the reduction capacity to both furaldehydes was increased when the polar amino acid serine was reverted back to the original hydrophobic amino acid leucine. Finally, mutation S110P could not by itself generate activity against HMF as demonstrated with natAdh1p-m110, but it proved to be important for HMF reduction since reversion of the mutation in mutAdh1p-rev110 led to significantly lower reduction activity. Also combining S110P and Y295C mutations (natAdh1p-m110, 295) led to a 4.6-fold increase in specific activity towards HMF. In contrast, this combination led to a 3-fold decrease in furfural reduction activity whereas both individual mutations gave higher furfural reduction levels than natAdh1p. Therefore the impact of mutation S110P appears to be dependent on the substrate and the presence of other surrounding mutations. It should be emphasized however, that is not possible to explain the

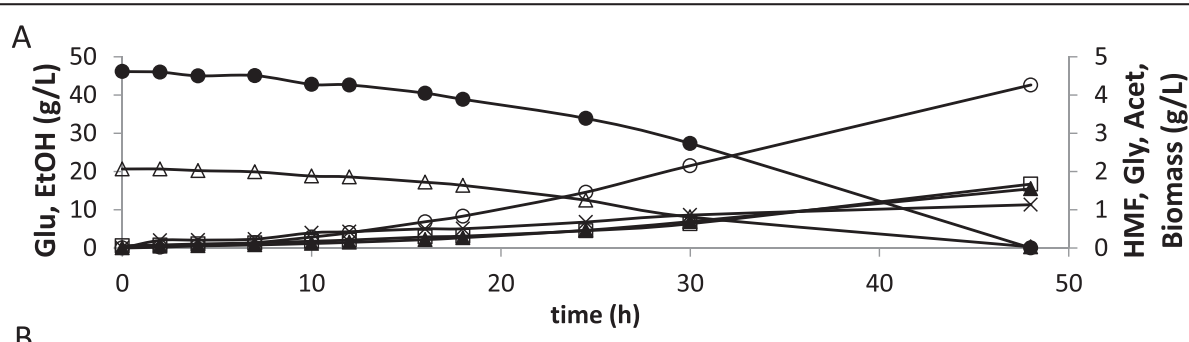

B

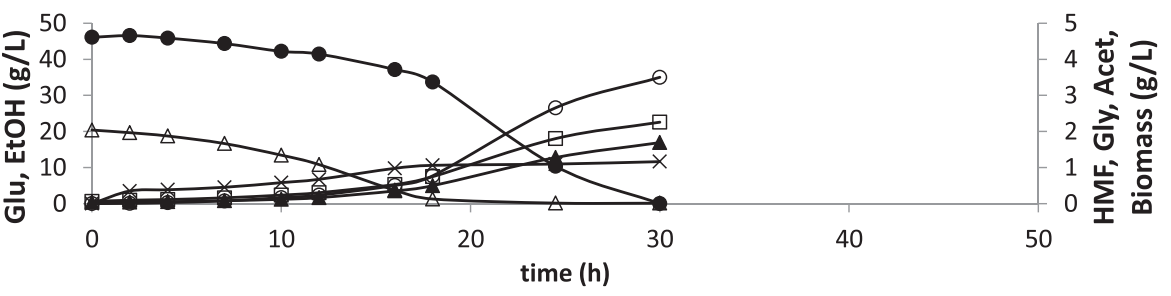

C

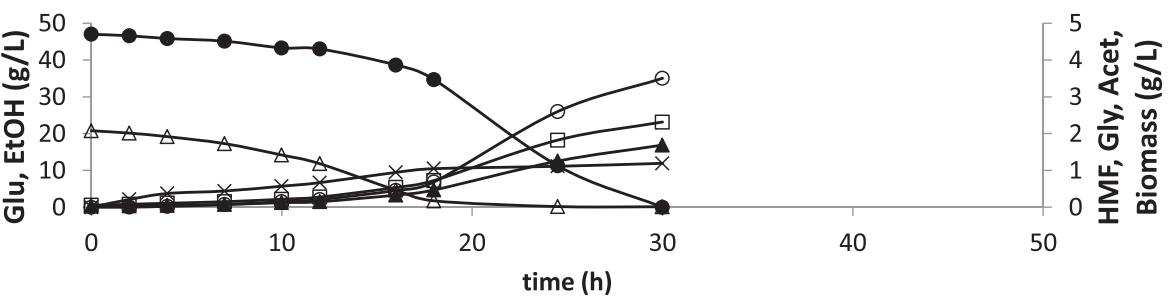

Figure 3 Comparison of glucose/HMF consumption and acetate/glycerol/ethanol/biomass formation during anaerobic cultivations in the presence of HMF for the control strain (A) and strains CEN.PK 113 5D [mutAdh1p] (B) and CEN.PK 113 5D [natAdh1p-mut110, 295] (C). Legend: - -glucose, o-glycerol, X-acetate, $\mathbf{\Delta}$-ethanol, $\triangle$-HMF, 口-biomass. The experiment was performed in biological duplicates and the figure shows the data of one representative profile for each strain. The standard deviation between replicates was less than $15 \%$. 
Table 6 Ethanol, biomass, glycerol and acetate yields in anaerobic batch fermentation in defined mineral medium with $40 \mathrm{~g} / \mathrm{l}$ glucose and supplemented with $2 \mathrm{~g} / \mathrm{l} \mathrm{HMF}$

\begin{tabular}{llll}
\hline Strain & $Y_{\text {ethanol }}$ & $Y_{\text {biomass }}$ & \multicolumn{1}{c}{$\mathbf{Y}_{\text {acetate }}$} \\
\hline Control & $0.38 \pm 0.06$ & $0.04 \pm 0.01$ & $0.10 \pm 0.01$ \\
CEN.PK 113-5D [Adh1 (59, 110, 117, 148, 152, 295)] & $0.41 \pm 0.06$ & $0.05 \pm 0.01$ & $0.09 \pm 0.02$ \\
CEN.PK 113-5D [Adh1 (110, 295)] & $0.38 \pm 0.04$ & $0.05 \pm 0.01$ & $0.08 \pm 0.01$ \\
\hline
\end{tabular}

Yields are expressed as $\mathrm{g}$ of product per $\mathrm{g}$ of glucose. Presented values are the mean of two independent biological replicates \pm standard deviation.

changes in activities obtained among the variants solely from the changes in the primary structure of the proteins. Although some changes in the protein properties can be inferred by the differences in the properties of the amino acids that have been altered (e.g. polarity and charge), the final effect that such changes can have in the biological function of the enzyme requires a deeper analysis. The prediction of possible relevant changes in the tertiary structures of the protein (for example in the active site or co-factor binding site) based on the mutations here described goes beyond the aim of this study.

Kinetic measurements also revealed important additional features for the mutations. First it enabled the analysis of the influence of the three mutations previously reported in natAdh1p at positions 59, 148 and 152 [15]. For example, the activity of mutAdh1p-rev117 with HMF was only $27 \%$ of that with acetaldehyde, while for natAdh1pm110, 295 the activity with HMF was close to $70 \%$ of the activity obtained with acetaldehyde. Considering that these variants have the same amino acids positions at 110 , 117 and 295 but differ by amino acids at positions 59, 148 and 152, the relevance of these three mutations on the enzymes properties was proven. The kinetic characterization also gave insights on how the alterations in particular amino acids affected the inhibition properties of the enzymes by the three analyzed substrates. For instance, although mutAdh1p-rev110, 117showed the relatively highest activity with furfural, it was inhibited by this substrate at very low concentrations $(\sim 1 \mathrm{mM})$ suggesting that the use of this variant for detoxification of high-furfural containing hydrolysates (up to $20 \mathrm{mM}$; [3]) would probably be limited.

The use of yeast strains with enhanced levels of furaldehyde reductases has proven to be a successful strategy for minimizing the negative effects of different compounds present in lignocellulosic hydrolysates $[17,20]$. In general, higher in vitro conversion rates of HMF (and furfural) have been correlated with improved fermentation performances in the presence of these inhibitors [6,21]. In our study, the in vivo HMF specific uptake rate could indeed be increased from $0.14 \mathrm{~g} / \mathrm{g}$ cell. $\mathrm{h}$ (control strain) to a maximum value of $0.48 \mathrm{~g} / \mathrm{g}$ cell.h when overexpressing $A D H 1$ variants. However, the laboratory strain expressing the most promising mutant, natAdh1p-m110, 295, did not show better in vivo performances than its counterpart expressing the original mutated gene during anaerobic fermentation on glucose in the presence of $2 \mathrm{~g} / \mathrm{l} \mathrm{HMF}$, despite higher measured Vmax for natAdh1pn110, 295. Nilsson et al. [22] obtained similar results during fed-batch fermentation with HMF. In that case, the in vivo conversion rate equaled the total reduction capacity of the cells for a poorly performing strain whereas the total in vitro enzyme activity was much higher than the specific in vivo uptake rate of HMF for the industrial isolate TMB3000 that carries $A D H 1$ original mutant. Taken together, these results suggest that there may be a limit above which the specific uptake rate of HMF cannot be improved by further increasing the reduction capacity of the cells. The adaptation response of $S$. cerevisiae to HMF has been shown to involve different components including inhibitor detoxification, alteration of pathways for ATP production and co-factor regeneration, transportation of toxic metabolites and degradation of damaged proteins [23]. Transcriptome studies have shown that multidrug-transporters were up-regulated in the presence of furaldehydes [24], but there is not information available on how fast the reduced forms of the furaldehydes are transported outside the cells and on the level of inhibition caused by these compounds. The availability of cofactors inside the cells may also explain the limitation observed in the in vivo HMF conversion. In contrast to in vitro enzymatic assays, where the co-factors are added in excess and the reaction under study is "isolated" from other cells reactions, the intracellular concentrations of co-factors are carefully balanced and regulated by the many other reactions in which both pairs, NADH/NAD ${ }^{+}$and NADPH/NADP ${ }^{+}$ participate [25]. It has recently been shown that when yeast cells were grown in chemostat in the presence of HMF and furfural, the levels of both $\mathrm{NAD}(\mathrm{P}) \mathrm{H}$ and $\operatorname{NAD}(\mathrm{P})^{+}$were perturbed and a reduction in biosynthetic capacity was observed, due to the drainage of NADPH in the presence of the aldehydes [26]. In another study, the NADH-specific conversion of HMF led to reduced glycerol and increase biomass formation in a continuous cultivation with defined mineral medium [17], which could indicate a competition for $\mathrm{NADH}$ usage. So the co-factor used during furaldehyde reduction may impact the product distribution in favor of either NADH or NADPH consuming routes. And under the stress imposed 
by the presence of HMF, the cells overexpressing $A D H 1$ variants may be able to use the available NADH for reduction purposes only as long as the regeneration of this cofactor can take place and at a fast enough rate.

\section{Conclusions}

The results presented here unravel the impact of single mutations on the substrate specificity of a key S. cerevisiae metabolic enzyme and identify tyrosine 295 as the key amino acid to mutate for getting HMF reduction capacity. From a more applied perspective, the results reaffirm that high reduction capacity is a relevant trait for furaldehyde bio-detoxification. Combination of this feature with further improvements in other type of mechanisms involved in inhibitor tolerance, will lead to the development of more robust strains for 2nd generation chemical production.

\section{Materials and methods}

\section{Strains and cultivation conditions}

Saccharomyces cerevisiae strains are summarized in Table 2. The strains were stored in $15 \%$ glycerol at $-80^{\circ} \mathrm{C}$. Cells from freshly streaked SD-ura plates [27] were used for pre-culture inoculation. Escherichia coli strain DH5 $\alpha$ (Life Technologies, Rockville, MD, USA) that was used for cloning purposes was grown in Luria-Bertani medium [27] supplemented or not with ampicillin $(50 \mu \mathrm{g} / \mathrm{mL})$ and also stored in $15 \%$ glycerol at $-80^{\circ} \mathrm{C}$.

\section{Molecular biology methods}

Competent E. coli cells were prepared using the Inoue method [28]. Transformants were selected on LB plates [27] containing $50 \mu \mathrm{g} / \mathrm{mL}$ ampicillin (ICN Biomedicals, Aurora, OH, USA). The lithium acetate method was used for transformation of S. cerevisiae [29]. Transformants were selected on SD-ura [27] plates. Restriction enzymes, T4-nucleotide ligase and shrimp alkaline phosphatase were purchased from Fermentas (Vilnius, Lithuania) whereas Pwo polymerase was purchased from Roche Diagnostics AB (Bromma, Sweden). All enzymes were used according to the manufacturers' recommendations. PCR fragments were purified using the E.Z.N.A cycle-pure kit (Omega Bio-Tek, Doraville, GA, USA). Plasmids were prepared using the QIAprep Spin Miniprep Kit (Qiagen, Hilden, Germany). DNA sequencing was performed using the Abi-Prism BigDye cycle sequencing kit (Applied Biosystems, Weiterstadt, Germany). Plasmid YEplacHXT [17] was used for cloning steps, its constitutive truncated HXT promoter [30] governing the overexpression of ORFs. Plasmids used in this study are described in Table 7.

\section{Native $A D H 1$ cloning}

Extraction of genomic DNA from strain CEN.PK 113-5D was conducted using the Y-PER kit (Pierce, Rockford, IL,
USA) according to the manufacturer's recommendations. Amplification of native ADH1 from CEN.PK 113-5D genomic DNA was performed as previously described [10] using primers Sense BamHI and Antisense BglII (Table 8). The single resulting amplicon was cleaved with $B a m H I$ and BglII and used for ligation with previously doublecleaved and de-phosphorylated YEplacHXT plasmid.

\section{Site-directed mutagenesis}

For site directed mutagenesis, a two-step PCR was used for the generation of an ORF containing the correct nucleotide changes. Plasmids YEplacHXT-mutADH1 and YEplacHXT-natADH1 (Table 7) were used as PCR templates for reverse mutagenesis of mutated $A D H 1$ from TMB3000 and mutagenesis of native $A D H 1$ from CEN.PK 113-5D, respectively. Table 8 lists the primers used for PCR mediated mutagenesis. The first round combined Sense BamHI and corresponding antisense primer and, a separate reaction with primers Antisense $B g l \mathrm{II}$ and corresponding sense primer. The two resulting amplicons were used in the second reaction as template with primers Sense BamHI and Antisense BglII. The resulting single amplicon was digested and ligated as described previously. All PCR reactions had an annealing step at $55^{\circ} \mathrm{C}, 1$ minute elongation time and 30 cycles. All Adh1p-variants are designated by the protein of origin (natAdh1p or mutAdh1p) followed by an indication of the position where the mutation or reversion was introduced. Therefore, natAdh1p-m295 refers to natAdh1p after mutagenesis at position 295; and mutAdh1p-rev117 refers to the mutAdh1p [10] after reverse mutagenesis of position 117 (Table 1). Strain names of either CEN.PK 113-5D or BY4741 hosts include their Adh1p designation in parentheses (Table 2).

\section{Protein extraction}

The cultures were grown until late exponential phase, and harvest at similar cellular densities. Cells were washed twice with double distilled water before being re-suspended in Y-PER detergent (Pierce), $1.7 \mathrm{ml} / \mathrm{g}$ cells. After gentle shaking at room temperature for 50 minutes the suspension was centrifuged for 20 minutes at 15,000 g. The lysate was collected for spectrophotometric assays. Protein concentration was determined with the Coomassie protein assay reagent (Pierce) in the Bradford assay according to the manufacturer's recommendations.

\section{Alcohol dehydrogenase activity and kinetics}

$\mathrm{NADH}$-dependent aldehyde reduction was determined according to [32], using $200 \mu \mathrm{M}$ NADH. All measurements were performed in biological duplicates and technical triplicates at $30^{\circ} \mathrm{C}$ in a U-2000 spectrophotometer (Hitachi, Tokyo, Japan). Reduction kinetics was determined for acetaldehyde (range $500 \mu \mathrm{M}-100 \mathrm{mM}$ ), furfural 
Table 7 Plasmids used in the study

\begin{tabular}{lll}
\hline Plasmid & Construction background & Reference \\
\hline YEplacHXT (reference plasmid) & YEplac195, HXT7p-PGKt URA3 & {$[31]$} \\
YEplacHXT-natADH1 & YEplacHXT, native ADH1 & This study \\
YEplacHXT-mutADH1 & YEplacHXT, mutated ADH1 & {$[10]$} \\
YEplacHXT-mutADH1-rev110 & YEplacHXT, mutated ADH1, P110S & This study \\
YEplacHXT-mutADH1-rev117 & YEplacHXT, mutated ADH1, S117L & This study \\
YEplacHXT-mutADH1-rev295 & YEplacHXT, mutated ADH1, C295Y & This study \\
YEplacHXT-natADH1-m110 & YEplacHXT, native ADH1, S110P & This study \\
YEplacHXT-natADH1-m295 & YEplacHXT, native ADH1, Y295C & This study \\
YEplacHXT-natADH1-m110,295 & YEplacHXT, native ADH1, Y295C, S110P & This study \\
YEplacHXT-mutADH1-rev110, 117 & YEplacHXT, mutated ADH1, P110S, S117L & This study \\
\hline
\end{tabular}

(100 $\mu \mathrm{M}-20 \mathrm{mM})$ and HMF $(500 \mu \mathrm{M}-20 \mathrm{mM})$. For natAdh1p, furfural was used up to $40 \mathrm{mM}$. One unit (U) corresponds to $1 \mu \mathrm{mol}$ of $\mathrm{NADH}$ oxidized per min, at $30^{\circ} \mathrm{C}$ and $\mathrm{pH}$ 6.7. All the enzymatic activities are reported as unit of activity per milligram of total protein (U/mg total protein).

\section{Kinetic modeling}

Modeling was performed according to the MichaelisMenten equation with the addition of a substrate inhibition constant:

$$
V=\frac{V \max \cdot[S]}{K m+[S]+\frac{[S]^{2}}{K i}}
$$

where V is velocity; Vmax is maximal velocity; [S] is substrate concentration; $\mathrm{Km}$ is affinity constant; and $\mathrm{Ki}$ is substrate inhibition constant. Parameter value estimation was according to the least square method, using the solver function in Microsoft ${ }^{\circ}$ Excel 2002. HMF activity parameters for strain BY4741 [mutAdh1p-rev117] were estimated without the substrate inhibition constant due

Table 8 Primers used for site-directed mutagenesis

\begin{tabular}{ll}
\hline Primer name & Sequence (5'-3') \\
\hline P110S sense & GTGAATTGGTAACGATCCAACTGTCCTCACGC \\
P110S antisense & GCGTGAGGACAGTTGGATCGTTACCCAATCAC \\
S117L sense & CTGTCCTCACGCTGACTTGTCTGGTTACACCCAC \\
S117L antisense & GTGGGTGTACCAGACAAGTCAGCGTGAGGACAG \\
C295Y sense & CTCCATTGTTGGTCTTACGTCGGTAACAGAGCTG \\
C295Y antisense & CAGCTCTGTTACCGACGTAAGAACCAACAATGGAG \\
S110P sense & GGTAACGAACCCAACTGTC \\
S110P antisense & GACAGTTGGGTCGTTACC \\
Y295C sense & TTGGTTCTTGCGTCGGTAAC \\
Y295C antisense & GTTACCGACGCAAGAACAA \\
Sense BamHI & GGGGGGATCCATGTCTATCCCAGAAACTC \\
Antisense Bg/ll & CTTAGATCTTATTTAGAAGTGTCACAACG \\
\hline
\end{tabular}

to a clear discrepancy of the substrate inhibition model with actual data.

\section{Batch fermentation with HMF}

Inoculum cultures were grown overnight at $30^{\circ} \mathrm{C}$ in $1 \mathrm{~L}$ cotton plugged shake-flasks with $100 \mathrm{~mL}$ of double concentrated defined mineral medium [33] supplemented with $40 \mathrm{~g} / \mathrm{L}$ glucose and $50 \mathrm{mM}$ potassium hydrogen phthalate buffer (adjusted to $\mathrm{pH} 5.5$ with potassium hydroxide) The same medium was used in batch experiments, without the buffer and, when indicated, with $2 \mathrm{~g} / \mathrm{L}$ HMF. The starting $\mathrm{OD}_{620}$ was 0.2 . Fermentation was carried out in $800 \mathrm{ml}$ medium at $30^{\circ} \mathrm{C}$ in $1.4 \mathrm{~L}$ Multifors bioreactor (Infors, Switzerland). Anaerobic conditions were maintained by continuously sparging $0.2 \mathrm{~L} / \mathrm{min} \mathrm{N}_{2}$ gas. The pH 5.5 was kept constant by addition of $3 \mathrm{M} \mathrm{KOH}$. The stirring rate was $200 \mathrm{rpm}$.

\section{Analysis of fermentation data}

Samples for metabolites and OD were regularly withdrawn from the reactor. For biomass determination, $5 \mathrm{~mL}$ culture was washed with distilled water and dried on Gelman filters (ø $47 \mathrm{~mm}$ Supor-450, $0.45 \mu \mathrm{m}$ ) in a microwave oven $(350 \mathrm{~W})$ for 8 minutes. The biomass concentration was correlated with $\mathrm{OD}_{620}$ by dry weight measurements. Glucose, ethanol, HMF, glycerol and acetic acid were analysed by high performance liquid chromatography (HPLC; Waters Corporation, MA, USA) on an Aminex HPX-87H column (Bio-Rad, CA, USA) at $65^{\circ} \mathrm{C}$. The mobile phase was $5 \mathrm{mM}$ sulphuric acid with a flow of $0.6 \mathrm{~mL} / \mathrm{min}$. All compounds were detected with a refractive index detector (Shimadzu, Tokyo, Japan).

The specific HMF uptake rates were calculated according to the formula:

$$
\mathrm{q}_{\mathrm{hmf}}=\mu \cdot \mathrm{m}
$$

where:

$\mu=$ maximum specific growth rate $(1 / \mathrm{h})$ 
m: slope obtained after plotting HMF concentration (gHMF/L) in the Yaxis vs. cdw (g cell/L) in the $\mathrm{X}$-axis at each time point of the exponential phase.

\section{Abbreviations}

HMF: 5-(hydroxymethyl)furfural; OD: Optical density; SD-ura: Synthetic defined without uracil; cdw: Cell dry weight; HPLC: High performance liquid chromatography; qPCR: Quantitative polymerase chain reaction.

\section{Competing interests}

The author(s) declare that they have no competing interests.

\section{Authors' contributions}

BL, PR and MGG designed the study; BL, WW, AJC and JRA performed the experiments and analyzed the results. BL and WW drafted the manuscript. All authors read and approved the final manuscript.

\section{Acknowledgements}

We wish to thank Prof. Bärbel Hahn-Hägerdal for her valuable comments and critically reading the manuscript. This project was financed by the Swedish Energy Agency.

\section{Author details}

Applied Microbiology, Department of Chemistry, Lund University, P.O. Box 124, SE-22100 Lund, Sweden. ${ }^{2}$ Department of Chemistry-BMC, Uppsala University, Box 576, SE-751 23 Uppsala, Sweden. ${ }^{3}$ Embrapa Agroenergy, Parque Estação Biológica, PqEB, W3 Norte (Final), 70770-901 Brasília, DF, Brazil.

Received: 19 November 2013 Accepted: 23 July 2014

Published: 9 August 2014

\section{References}

1. Gray KA, Zhao L, Emptage M: Bioethanol. Curr Opin Chem Biol 2006, 10:141-146

2. Hahn-Hägerdal B, Galbe M, Gorwa-Grauslund MF, Lidén G, Zacchi G: Bio-ethanol-the fuel of tomorrow from the residues of today. Trends Biotechnol 2006, 24:549-556.

3. Almeida JRM, Modig T, Petersson A, Hahn-Hägerdal B, Lidén G, Gorwa-Grauslund MF: Increased tolerance of inhibitors in lignocellulosic hydrolysates by Saccharomyces cerevisiae. J Chem Technol Biotechnol 2007, 82:340-349

4. Dunlop AP: Furfural formation and behavior. Ind Eng Chem 1948, 40:204-209.

5. Ulbricht RJ, Northup SJ, Thomas JA: A review of 5-hydroxymethylfurfural (HMF) in parenteral solutions. Fundam Appl Toxicol 1984, 4:843-853.

6. Taherzadeh MJ, Gustafsson L, Niklasson C, Lidén G: Physiological effects of 5-hydroxymethylfurfural on Saccharomyces cerevisiae. Appl Microbiol Biotechnol 2000, 53:701-708.

7. Larsson S, Palmqvist E, Hahn-Hägerdal B, Tengborg C, Stenberg K, Zacchi G, Nilvebrant $\mathrm{N}-\mathrm{O}$ : The generation of fermentation inhibitors during dilute acid hydrolysis of softwood. Enzym Microb Technol 1999, 24:151-159.

8. Modig T, Liden G, Taherzadeh MJ: Inhibition effects of furfural on alcohol dehydrogenase, aldehyde dehydrogenase and pyruvate dehydrogenase. Biochem J 2002, 363:769-776.

9. Liu ZL, Slininger PJ, Dien BS, Berhow MA, Kurtzman CP, Gorsich SW: Adaptive response of yeasts to furfural and 5-hydroxymethylfurfural and new chemical evidence for HMF conversion to 2,5-bis-hydroxymethylfuran. J Ind Microbiol Biotechnol 2004, 31:345-352.

10. Laadan B, Almeida JR, Radstrom P, Hahn-Hagerdal B, Gorwa-Grauslund M: Identification of an $\mathrm{NADH}$-dependent 5-hydroxymethylfurfural-reducing alcohol dehydrogenase in Saccharomyces cerevisiae. Yeast 2008, 25:191-198.

11. Linden T, Peetre J, Hahn-Hägerdal B: Isolation and characterization of acetic acid-tolerant galactose-fermenting strains of Saccharomyces cerevisiae from a spent sulfite liquor fermentation plant. Appl Environ Microbiol 1992, 58:1661-1669.


Osterman J, Denis C, Cox D, Beier D: The alcohol dehydrogenase genes of the yeast, Saccharomyces cerevisiae: isolation, structure, and regulation. Basic Life Sci 1982, 19:335-361.
13. Grey $\mathrm{M}, \mathrm{Sch}$ midt $\mathrm{M}$, Brendel $\mathrm{M}$ : Overexpression of $A D H 1$ confers hyper-resistance to formaldehyde in Saccharomyces cerevisiae. Curr Genet 1996, 29:437-440.

14. Almeida JR, Runquist D, Sànchez I, Nogué V, Lidén G, Gorwa-Grauslund MF: Stress-related challenges in pentose fermentation to ethanol by the yeast Saccharomyces cerevisiae. Biotechnol J 2011, 6(3):286-299.

15. Jörnvall $H$ : The primary structure of yeast alcohol dehydrogenase. Eur J Biochem 1977, 72:425-442.

16. van Dijken JP, Bauer J, Brambilla L, Duboc P, Francois JM, Gancedo C, Giuseppin ML, Heijnen JJ, Hoare M, Lange HC, Madden EA, Niederberger P, Nielsen J, Parrou JL, Petit T, Porro D, Reuss M, van Riel N, Rizzi M, Steensma $H Y$, Verrips $C T$, VindeløV J, Pronk JT: An interlaboratory comparison of physiological and genetic properties of four Saccharomyces cerevisiae strains. Enzym Microb Technol 2000, 26:706-714.

17. Almeida JM, Röder A, Modig T, Laadan B, Lidén G, Gorwa-Grauslund M-F: $\mathrm{NADH}$ - vs NADPH-coupled reduction of 5-hydroxymethyl furfural (HMF) and its implications on product distribution in Saccharomyces cerevisiae. Appl Microbiol Biotechnol 2008, 78:939-945.

18. Ishii J, Yoshimura K, Hasunuma T, Kondo A: Reduction of furan derivatives by overexpressing NADH-dependent Adh1 improves ethanol fermentation using xylose as sole carbon source with Saccharomyces cerevisiae harboring XR-XDH pathway. Appl Microbiol Biotechnol 2013, 97:2597-2607.

19. Jörnvall $H$, Eklund $H$, Branden Cl: Subunit conformation of yeast alcohol dehydrogenase. J Biol Chem 1978, 253:8414-8419.

20. Liu ZL: Molecular mechanisms of yeast tolerance and in situ detoxification of lignocellulose hydrolysates. Appl Microbiol Biotechnol 2011, 90:809-825.

21. Modig T, Almeida JR, Gorwa-Grauslund MF, Lidén G: Variability of the response of Saccharomyces cerevisiae strains to lignocellulose hydrolysate. Biotechnol Bioeng 2008, 100:423-429.

22. Nilsson A, Gorwa-Grauslund MF, Hahn-Hägerdal B, Lidén G: Cofactor dependence in furan reduction by Saccharomyces cerevisiae in fermentation of acid-hydrolyzed lignocellulose. Appl Environ Microbiol 2005, 71:7866-7871.

23. Ma M, Liu ZL: Comparative transcriptome profiling analyses during the lag phase uncover YAP1, PDR1, PDR3, RPN4, and HSF1 as key regulatory genes in genomic adaptation to the lignocellulose derived inhibitor HMF for Saccharomyces cerevisiae. BMC Genomics 2010, 11:660

24. Sundström L, Larsson S, Jönsson L: Identification of Saccharomyces cerevisiae genes involved in the resistance to phenolic fermentation inhibitors. Appl Biochem Biotechnol 2010, 161:106-115.

25. Heux S, Cachon R, Dequin S: Cofactor engineering in Saccharomyces cerevisiae: expression of a $\mathrm{H} 2 \mathrm{O}-$ forming $\mathrm{NADH}$ oxidase and impact on redox metabolism. Metab Eng 2006, 8:303-314.

26. Ask M, Bettiga M, Mapelli V, Olsson L: The influence of HMF and furfural on redox-balance and energy-state of xylose-utilizing Saccharomyces cerevisiae. Biotechnol Biofuels 2013, 6:22.

27. Ausubel FA, Brent R, Kingston RE, Moore DD, Seidman JG, Smith JA, Struhl K (Eds): Current Protocols in Molecular Biology. New York: John Wiley \& Sons, Inc; 1995.

28. Inoue $H$, Nojima $H$, Okayama $H$ : High efficiency transformation of Escherichia coli with plasmids. Gene 1990, 96:23-28.

29. Gietz D, St Jean A, Woods RA, Schiestl RH: Improved method for high efficiency transformation of intact yeast cells. Nucleic Acids Res 1992, 20:1425.

30. Hauf J, Zimmermann FK, Muller S: Simultaneous genomic overexpression of seven glycolytic enzymes in the yeast Saccharomyces cerevisiae. Enzym Microb Technol 2000, 26:688-698.

31. Karhumaa K, Hahn-Hägerdal B, Gorwa-Grauslund MF: Investigation of limiting metabolic steps in the utilization of xylose by recombinant Saccharomyces cerevisiae using metabolic engineering. Yeast 2005, 22:359-368.

32. Wahlbom CF, Hahn-Hägerdal B: Furfural, 5-hydroxymethyl furfural, and acetoin act as external electron acceptors during anaerobic fermentation of xylose in recombinant Saccharomyces cerevisiae. Biotechnol Bioeng 2002, 78:172-178.

33. Verduyn C, Postma E, Scheffers WA, Van Dijken JP: Effect of benzoic acid on metabolic fluxes in yeasts: a continuous-culture study on the regulation of respiration and alcoholic fermentation. Yeast 1992, 8:501-517.

doi:10.1186/s12934-014-0112-5

Cite this article as: Laadan et al:: Furaldehyde substrate specificity and kinetics of Saccharomyces cerevisiae alcohol dehydrogenase 1 variants. Microbial Cell Factories 2014 13:112. 